Gut, 1986, 27, 1169-1172

\title{
Faecal metronidazole concentrations during oral and intravenous therapy for antibiotic associated colitis due to Clostridium difficile
}

\author{
R P BOLTON AND M A CULSHAW \\ From the University Department of Medicine and Department of Pharmacy, St James's Hospital, Leeds
}

SUMMARY Faecal metronidazole and hydroxymetronidazole concentrations measured by high pressure liquid chromatography are reported during 10 episodes of Clostridium difficile colitis in nine patients. Bactericidal faecal concentrations were present in all patients with acute disease receiving oral or intravenous metronidazole, and all responded to therapy. Metronidazole and hydroxymetronidazole concentrations fell as the diarrhoea improved and neither substance was detectable in the faeces of five patients after recovery. This demonstration of intracolonic therapeutic concentrations of metronidazole supports the clinical experience of oral metronidazole being effective in the treatment of antibiotic associated diarrhoea caused by $C$ difficile and also suggests a potential role for intravenous metronidazole in this disease.

Metronidazole has been proposed as an effective alternative to vancomycin in the treatment of Clostridium difficile induced pseudomembraneous colitis and antibiotic associated diarrhoea. ${ }^{1}$ Initial anecdotal reports ${ }^{2} 3$ have been followed by more detailed studies $^{4-6}$ and a randomised controlled trial of 101 patients reported oral metronidazole to be equally effective with vancomycin in the treatment of this condition, ${ }^{7}$ although the statistical conclusions of this study have been questioned. ${ }^{8}$

Doubt as to the efficacy of metronidazole has been expressed on theoretical grounds, however, largely based on its rapid and usually complete absorption from the upper gut after oral therapy. ${ }^{9}$ Proliferation of $C$ difficile occurs within the colon and its pathology is thought to be toxin induced as tissue invasion by the organism does not occur. ${ }^{10}$ Effective antimicrobial therapy therefore requires bactericidal intracolonic concentrations, and whilst this has been documented after oral vancomycin, ${ }^{9}$ which is not absorbed, there have been no reports to date for metronidazole.

Information on the concentration of metronidazole in faeces is scanty. In healthy volunteers faecal metronidazole is usually undetectable after oral administration. ${ }^{11}$ In patients with active colonic

Address for correspondence: Dr R P Bolton, Dept of Medicine, St. James`s University Hospital, Leeds LS9 7TF.

Received for publication 27 January 1986.
Crohn's disease therapeutic concentrations of metronidazole have been documented in the faeces, with higher concentrations being found in those patients with more extensive disease. ${ }^{12} \mathrm{We}$ now report a study of nine patients with $C$ difficile colitis in whom we have measured faecal metronidazole concentrations during treatment.

\section{Methods}

PATIENTS

Nine patients with 10 episodes of documented toxin and culture positive $C$ difficile diarrhoea received treatment with metronidazole. Treatment was oral in seven and intravenous in three. Patient details are shown in the Table.

Random faecal samples, free from urinary contamination, were stored at $-20^{\circ} \mathrm{C}$ before assay. A weighed aliquot of each stool sample was freeze dried and the percentage of stool water calculated.

Detection of metronidazole and its principal metabolite, hydroxy-metronidazole, was carried out using high pressure liquid chromatography. Briefly, freeze-dried faecal samples were extracted with ether and reconstituted in methanol after evaporation to dryness. Samples were analysed using a Varian 5000 liquid chromatograph with a Rad Pak A C18, ODS, $10 \mu \mathrm{m}$ column (Waters Associates, Hartford). The mobile phase was $20 \%$ methanol in $0.01 \mathrm{M}$ di-ammonium hydrogen phosphate $(\mathrm{pH} 7)$ 
and the UV detector wave length set at $320 \mathrm{~mm}$. All determinations were carried out in duplicate, and known standards included. The efficiency of the extraction of metronidazole from freeze dried faeces was established as $80 \%$ for metronidazole and $52 \%$ for hydroxymetronidazole. The minimum detectable concentrations of metronidazole and hydroxymetronidazole in freeze dried faeces were $2.5 \mu \mathrm{g} / \mathrm{g}$ and $5.0 \mu \mathrm{g} / \mathrm{g}$ respectively. The standard calibration curves were linear over the range investigated.

Results are expressed as concentrations per gram of freeze dried faeces, and per gram wet weight for clinical interpretation.

Statistical analysis was carried out using the Mann Whitney U test.

\section{Results}

Faecal metronidazole and hydroxymetabolite con- centrations showed wide interpatient variation, and were similar during oral or intravenous therapy (Table). Metronidazole was detectable in all nine watery samples (mean $9.3 \pm 7.5 \mu \mathrm{g} / \mathrm{g}$ wet weight; range $0 \cdot 8-24 \cdot 2$ ), in all seven semiformed samples (mean $3.3 \pm 3.6 \mu \mathrm{g} / \mathrm{g}$ wet weight; range $0.5-10 \cdot 4$ ), and in six of 13 formed faecal samples (mean $1.23 \pm 2.8 \mu \mathrm{g} / \mathrm{g}$; range $0-10 \cdot 2)$. Hydroxymetabolite was detectable in eight of nine watery samples (mean 12.3-19.5 $\mu \mathrm{g} / \mathrm{g}$ wet weight; range $0-62.4$ ), in all seven semiformed samples (mean $3.68 \pm 4.2 \mu \mathrm{g} / \mathrm{g}$; range $0 \cdot 65-12 \cdot 6$ ), and in five of 13 formed faecal samples (mean $1.8 \pm 4.6 \mu \mathrm{g} / \mathrm{g}$; range $0-16.8$ ) (Figure). Faecal concentrations in watery or semiformed samples were not significantly different for metronidazole and hydroxymetabolite, but concentrations of both were significantly higher in water and semi-formed samples than in formed faecal samples $(p<0.05-p<0.002$, Figure $)$.

Table Clinical details and faecal metronidazole $(M Z)$ and hydroxymetabolite $(O H)$ levels in nine patients during metronidazole therapy for documented $\mathrm{C}$ difficile colitis

\begin{tabular}{|c|c|c|c|c|c|c|c|c|c|c|c|c|c|c|}
\hline \multirow[b]{3}{*}{$P t$} & \multirow[b]{3}{*}{ Sex } & \multirow[b]{3}{*}{$\begin{array}{l}\text { Age } \\
(y r)\end{array}$} & \multirow[b]{3}{*}{ Diagnosis } & \multirow[b]{3}{*}{$\underset{*}{\text { Histology }}$} & \multirow{2}{*}{\multicolumn{3}{|c|}{ Metronidazole }} & \multirow{2}{*}{\multicolumn{3}{|c|}{ Stool }} & \multicolumn{4}{|c|}{ Faecal Concentrations $(\mu g / g)$} \\
\hline & & & & & & & & & & & \multicolumn{2}{|l|}{ Dry } & \multicolumn{2}{|l|}{ Wet } \\
\hline & & & & & $\begin{array}{l}\text { Dosage } \\
\text { mg tds }\end{array}$ & Route & $\begin{array}{l}\text { Days of } \\
\text { therapy }\end{array}$ & $\begin{array}{l}\text { Frequency } \\
\text { /day }\end{array}$ & $\begin{array}{l}\text { Consist- } \\
\text { ency }{ }^{\dagger}\end{array}$ & $\begin{array}{l}\% \text { age } \\
\text { water }\end{array}$ & $\mathrm{OH}$ & $M Z$ & $\overline{\mathrm{OH}}$ & $M Z$ \\
\hline \multirow[t]{7}{*}{1} & $\mathbf{F}$ & 69 & Crohn's disease & PMC & 400 & 0 & 3 & $>10$ & W & 93 & $7 \cdot 4$ & $31 \cdot 3$ & 0.5 & $2 \cdot 2$ \\
\hline & & & sclerosing & & & & 10 & 6 & SF & 93 & 21.8 & $32 \cdot 6$ & 1.5 & $2 \cdot \overline{3}$ \\
\hline & & & cholangitis & & & & 18 & 3 & SF & 91 & $16 \cdot 2$ & 4.9 & $1 \cdot 5$ & 0.4 \\
\hline & & & Recurrence & PMC & 400 & 0 & 2 & 2 & SF & 88 & $5 \cdot 4$ & 3.9 & 0.65 & 0.5 \\
\hline & & & & & & & 4 & 2 & SF & 90 & $38 \cdot 2$ & $30 \cdot 8$ & $3 \cdot 8$ & $3 \cdot 1$ \\
\hline & & & & & & & 9 & 2 & $\mathbf{F}$ & 80 & 4.9 & $3 \cdot 2$ & 0.98 & 0.6 \\
\hline & & & & & & & 10 & 1 & $\mathrm{~F}$ & 81 & 0 & 0 & 0 & 0 \\
\hline \multirow[t]{3}{*}{2} & $\mathbf{F}$ & 61 & Bronco- & NS & 200 & 0 & 7 & 2 & $\mathrm{~F}$ & 85 & 0 & 0 & 0 & 0 \\
\hline & & & pneumonia & & & & 10 & 1 & $F$ & 83 & $11 \cdot 1$ & $12 \cdot 0$ & 1.9 & $2 \cdot 0$ \\
\hline & & & & & & & 17 & 1 & $\mathrm{~F}$ & 83 & 0 & 0 & 0 & 0 \\
\hline \multirow[t]{4}{*}{3} & $\mathbf{M}$ & 44 & Hepatic abscess & PMC & 400 & 0 & 1 & $>10$ & W & 85 & 0 & $5 \cdot 1$ & 0 & $0 \cdot 8$ \\
\hline & & & Cholangitis & & & & 3 & 6 & SF & 83 & $5 \cdot 4$ & $5 \cdot 6$ & 0.92 & 0.95 \\
\hline & & & & & & & 4 & 3 & $\mathrm{~F}$ & 84 & 0 & 0 & 0 & 0 \\
\hline & & & & & & & 9 & 2 & $\mathrm{~F}$ & 79 & 0 & 0 & 0 & 0 \\
\hline \multirow[t]{3}{*}{4} & $\mathbf{F}$ & 79 & Pneumonia & NA & 400 & 0 & 2 & 12 & w & 96 & $38 \cdot 6$ & $217 \cdot 4$ & $1 \cdot 5$ & 8.7 \\
\hline & & & & & & & 7 & 4 & w & 96 & 1560 & $371 \cdot 5$ & $62 \cdot 4$ & $14 \cdot 9$ \\
\hline & & & & & & & 11 & 1 & $\mathrm{~F}$ & 90 & $167 \cdot 5$ & $101 \cdot 6$ & $16 \cdot 8$ & $10 \cdot 2$ \\
\hline \multirow[t]{3}{*}{5} & $\mathbf{F}$ & 75 & Cholecystectomy & NS & 400 & 0 & 2 & 8 & w & 93 & 88.6 & $61 \cdot 4$ & $6 \cdot 2$ & $4 \cdot 3$ \\
\hline & & & & & & & 7 & 2 & $\mathbf{F}$ & 78 & 0 & 2.7 & 0 & 0.6 \\
\hline & & & & & & & 10 & 1 & $\mathrm{~F}$ & 78 & 0 & 0 & 0 & 0 \\
\hline \multirow[t]{3}{*}{6} & $\mathbf{M}$ & 52 & Cellulitis & PMC & 400 & 0 & 2 & 10 & w & 91 & $65 \cdot 6$ & $82 \cdot 2$ & $5 \cdot 9$ & $7 \cdot 4$ \\
\hline & & & & & & & 4 & 3 & SF & 86 & $90 \cdot 0$ & $74 \cdot 3$ & $12 \cdot 6$ & $10 \cdot 4$ \\
\hline & & & & & & & 7 & 1 & $\mathrm{~F}$ & 82 & $13 \cdot 3$ & $7 \cdot 2$ & $2 \cdot 4$ & $1 \cdot 3$ \\
\hline 7 & $\mathbf{F}$ & 40 & Cholangitis & PMC & 500 & iv & 4 & 12 & W & 98 & 460 & 1212 & $9 \cdot 2$ & $24 \cdot 2$ \\
\hline \multirow[t]{2}{*}{8} & $\mathbf{F}$ & 68 & Cholecystectomy & NS & 500 & iv & 2 & 10 & W & 94 & 140 & 105 & 8.4 & $6 \cdot 3$ \\
\hline & & & & & & & 5 & 2 & $\mathrm{~F}$ & 79 & 5.4 & $6 \cdot 2$ & $1 \cdot 1$ & $1 \cdot 3$ \\
\hline \multirow[t]{3}{*}{9} & $\mathbf{M}$ & 63 & Colonic resection & NA & 500 & iv & 2 & 8 & W & 92 & $203 \cdot 7$ & $186 \cdot 3$ & $16 \cdot 3$ & 14.9 \\
\hline & & & & & & & 4 & 2 & SF & 86 & $34 \cdot 3$ & $36 \cdot 4$ & $4 \cdot 8$ & $5 \cdot 1$ \\
\hline & & & & & & & 7 & 1 & $\mathbf{F}$ & 78 & 0 & 0 & 0 & 0 \\
\hline
\end{tabular}

${ }^{*} \mathrm{PMC}=$ Pseudomembranous colitis. $\mathrm{NS}=$ Non specific changes. $\mathrm{NA}=$ Not available. $+\mathrm{W}=\mathrm{Watery} . \mathrm{SF}=$ Semiformed. $\mathrm{F}=\mathrm{Formed}$ 




Figure Faecal concentrations of metronidazole $(M Z)$ and hydroxymetronidazole $(\mathrm{OH})$ [ $\mu \mathrm{g} / \mathrm{g}$ wet weight] during oral (O) and intravenous (O) metronidazole therapy.

\section{Discussion}

Reports of the clinical effectiveness of metronidazole in the treatment of $C$ difficile associated diarrhoea are supported by the present findings of therapeutic faecal concentrations during both oral and intravenous therapy. The minimum inhibitory concentration of metronidazole for $C$ difficile $(0 \cdot 25-1 \mathrm{mg} / \mathrm{l})^{13}{ }^{14}$ was well exceeded in most faecal samples taken during the acute illness, although concentrations fell during recovery (Table). The therapeutic contribution of hydroxymetronidazole must also be considered, as this principal metabolite of metronidazole is active against $C$ difficile in vitro with a minimum inhibitory concentration of between 0.5 and $4 \mathrm{mg} / \mathrm{l}$ (personal observations). When combined with the values for metronidazole, effective cidal antimicrobial concentrations were present in all patients with acute disease.

The source of intracolonic metronidazole remains uncertain. Rapid intestinal transit with reduced absorption $^{12}$ would not explain the presence of faecal metronidazole during intravenous therapy. Biliary excretion of metronidazole occurs in $\operatorname{man}^{15}$ and colonic reabsorption has been documented in rats. ${ }^{16}$ Ings et al, ${ }^{17}$ however, found a low enterohepatic circulation and concluded that after absorption, metronidazole was secreted directly through inflamed colonic mucosa.

The highest intracolonic accumulation of metronidazole might thus be expected in those patients with the most severe disease, but this is difficult to determine in the absence of complete faecal collections. Metronidazole and hydroxymetabolite concentrations in random faecal samples were unrelated to disease severity judged on the frequency of diarrhoea or presence of pseudomembranes at sigmoidoscopy (Table). In practice, it is the concentration of antibacterial per gram of wet weight stool which will determine the effectiveness of therapy. Cidal levels were achieved in the patients in the present study and all responded satisfactorily to treatment with metronidazole, symptomatic resolution being accompanied by toxin and organism clearance.

Faecal metronidazole and hydroxymetabolite concentrations decreased during recovery, with significantly lower concentrations in formed compared with semiformed or water stools (Figure). This is consistent with the return of normal drug handling as the mucosal inflammation resolved, and would account for the previous observations of undetectable faecal metronidazole in healthy volunteers. ${ }^{11}$

Successful treatment of $C$ difficile associated diarrhoea has been reported using intravenous metronidazole, ${ }^{14}$ and the present demonstration of therapeutic faecal metronidazole concentrations during parenteral therapy further supports this case. Oral therapy is occasionally impossible because of associated ileus or toxic dilatation, and the option for using intravenous metronidazole in these cases provides a valuable alternative to undertaking a defunctioning ileostomy or colectomy. Intravenous vancomycin appears ineffective. ${ }^{18}$

The occasional development of PMC after the use of metronidazole, usually in combination with other antibiotics, ${ }^{19}$ but also when used alone, ${ }^{20}$ should not preclude its use as an effective therapeutic agent. $C$ difficile associated diarrhoea may follow treatment with any antibacterial agent and pseudomembraneous colitis after vancomycin has also been described. ${ }^{21}$ Occasional treatment failures have been described with both metronidazole ${ }^{22}$ and with vancomycin,$^{23}$ and symptomatic relapse rates of around $15-20 \%$ can be expected after either therapy. ${ }^{624}$ 
We believe that the present findings strengthen the case for oral metronidazole, at a dosage of 400 $\mathrm{mg}$ eight hourly, to be considered as the first alternative to vancomycin in the treatment of pseudomembraneous colitis and diarrhoea due to $C$ difficile. Metronidazole also offers the added advantage of effective treatment when given intravenously at a dosage of $500 \mathrm{mg}$ eight hourly.

We thank May \& Baker Ltd, for the provision of analytical grade metronidazole and hydroxymetabolite for the HPLC assay.

\section{References}

1 George WL, Rolfe RD, Finegold SM. Treatment and prevention of antibiotic induced colitis and diarrhoea. Gastroenterology 1980; 79: 366-72.

2 Pashby NL, Bolton RP. Sherriff RJ. Oral metronidazole in the treatment of $\mathrm{C}$. difficile colitis. $\mathrm{Br}$ med $\mathrm{J}$ 1979; i: $16(05-6$.

3 Oldenburger D, Miller JA. Treatment of pseudomembranous colitis with oral metronidazole after relapse following vancomycin. Am J Gastroenterol 1980; 74: 359-60).

4 Bolton RP. Oral metronidazole in C. difficile-positive antibiotic-associated diarrhoea. [Abstract]. Gut 1980; 21: A921.

5 Nicolopoulos NG, Stathipoulos EN, Douzinas EE, Vassilikis JS. Pseudomembranous colitis: treatment with metronidazole. Hepato-Gastroenterol 1981; 28: 120-3.

6 Cherry RD, Portnoy D, Jabbari M, Daly DS, Kinnear DG, Goresky CA. Metronidazole: an alternative therapy for antibiotic-associated colitis. Gastroenterology 1982; 82: 849-51.

7 Teasley DG, Gerding DN, Olsen MM, et al. Prospective randomised trial of metronidazole vs vancomycin for C. difficile antibiotic associated diarrhoea and colitis. Lancet 1983; ii: 1043-6.

8 Gordon RS. Metronidazole or vancomycin for $\mathrm{C}$ difficile-associated diarrhoea. Lancet 1983; ii: 1417.

9 Keighley MRB, Burdon DW, Arabi Y, et al. Randomised controlled trial of vancomycin for pseudomembranous colitis and postoperative diarrhoea. $\mathrm{Br}$ Med J 1978; ii: 1667-70.
10 Trnka YM, Lamont JT. Clostridium difficile colitis. Adv Intern Med 1984; 29: 85-107.

11 Arabi Y, Dimock F, Burdon DW. Influence of neomycin and metronidazole on colonic microflora of volunteers. J Antimicrob Chemother 1979; 5: 521-7.

12 Krook A, Lindstrom B, Kjellander J, Jarnerot G, Bodin L. Relation between concentrations of metronidazole and Bacteroides spp in faeces of patients with Crohn's disease and healthy individuals. J Clin Pathol 1981; 34: 645-50.

13 Fekety R. Silva J, Toshniwal R, et al. Antibioticassociated colitis: effects of antibiotics and the disease in hamsters. Rev Infect Dis 1979; 1: 386-96.

14 Bolton RP. Clostridium difficile: a study of the organism and its role in diarrhoeal disease University of Bristol: MD Thesis, 1984.

15 Lykkesgaard NM, Jugtegen T. Excretion of metronidazole in human bile. Scand J Gastroenterol 1977; 12: 1003-5.

16 Populaire P, Benazet F, Pascal S, et al. Circulation et sort du metronidazole dans le tractus digestif chez le rat apres administation, par voie orale absorption du metronidazole per les digestives. Therapie 1971; 26: 581-4.

17 Ings RM, McFadzean JA, Ormerod WE. The fate of metronidazole and its implications in chemotherapy. Xenobiotica 1975 ; 5: 223-6.

18 Tedesco F, Markham R, Gurwith M, Christie D, Bartlett JG. Oral vancomycin for antibiotic-associated pseudomembranous colitis. Lancet 1978; ii: 226-8.

19 Borricllo SP, Larson HE. Antibiotic and pseudomembranous colitis. J Antimicrob Chemother 1981; 7: suppl A, 53-62.

20 Daly JJ, Chowdary KVS. Pseudomembranous colitis secondary to metronidazole. Dig Dis Sci 1983; 28: 573-4.

21 Rampling A, Warren RE, Berry PJ, Swirsky D, Hoggarth CE, Bevan PC. Atypical C. difficile colitis in neutropaenic patients. Lancet 1982; ii: 162-3.

22 Brown JR. Metronidazole and antibiotic-associated colitis. Br Med J 1981; ii: 1334.

23 Bartlett JG, Taylor NS, Chang TW, Dzink J. Clinical and laboratory observations in C. difficile colitis. $A m$ J Clin Nutr 1980; 33: 2521-6.

24 Fekety R, Silva J, Buggy B, Deery HG. Treatment of antibiotic-associated colitis with vancomycin. J Antimicrob Chemother 1984; 14: suppl D: 97-102. 